\title{
PALISADED ENCAPSULATED NEUROMA (PEN): A CASE REPORT
}

\author{
Samdurkar A $A^{*}$,Poudel $S^{* *}$, Regmi $S^{* *}$, Khurana $S^{* * *}$ \\ "Professor, "Resident, "'Intern \\ Department of Clinical Pathology, U.C.M.S. Teaching Hospital, Bhairahawa, Nepal
}

\section{ABSTRACT}

A growth or tumor of nerve is neuroma. Localised and circumscribed neuromas are termed as true neoplasm, as per James W. Patterson's quotation. Further, Palisaded encapsulated Neuroma (PEN) is a distinctive cutaneous nodular lesion often in the head, neck and face regions and are benign. They have schwannian and axonal components. A 30 year old male presented to surgical OPD with nodular enlargement in the scar behind the ear. Grossly these are usually pear shaped or bulb like dermal nodule. Microscopy showed peripheral circumscription for nodules of axonal and schwannian cells with predominance of fibroblastic component. Various references support above findings. And therefore, we arrived to a conclusion of this being PEN within scar tissue, as regards to clinical and histopathlogic peculiarities both gross and microscopic.

\section{INTRODUCTION}

A growth or tumor of nerve tissue is Neuroma. The term neuroma is ages old. Recent inclusion of the entity as true neoplasm when that is localized and circumscribed nodule often with fibrous capsule, is attracting attention. Palisaded encapsulated neuroma (PEN) is a distinctive cutaneous nodular lesion in the region of face ${ }^{8}$. There are several types of Neuroma that can arise in or involve the skin. Although traumatic neuroma has traditionally been considered the most common of these, in our surgical material, localized, circumscribed neuroma (formerly "Palisaded, Encapsulated" Neuroma) is seen most frequently. Localized, 
circumscribed neuromas are considered true neoplasms ${ }^{1}$. Palisaded encapsulated neuroma is a distinctive clinicopathologic entity that favors mucocutaneous junctions of facial skin of middle-aged patients without gender predilection ${ }^{2}$.

\section{CASE DETAILS}

A 30 year old male presented to surgical OPD with scar behind the ear. The scar was hypertrophic but soft measuring 4 $\mathrm{cm} \times 1 \mathrm{~cm}$ in size. The hypertrophic scar was resected and sent for histopathology. Gross examination revealed single specimen measuring 4.5 $x 1.5 \times 1 \mathrm{~cm}$, grayish brown in color, nodular, soft to firm in consistency. External surface showed stretched out skin with hair. The nodule measured 2.2 $x 1.3 \mathrm{~cm}$ and was pear shaped. The cut section showed white streaks (fig.1). Microscopic examination showed a thinned out squamous epithelium with lentigenous melanocytic hyperplasia, well circumscribed dermal tumors composed of variable sized fibrocollagenous nodules in close association with neurovascular bundles occasionally with Schwannomatoid features like nuclear palisade, circumferential fibrosis, peripheral rim of neuronal cells in one sector focal. At cut margins sweat glands are seen surrounded by fibrosis (fig.2, 3).

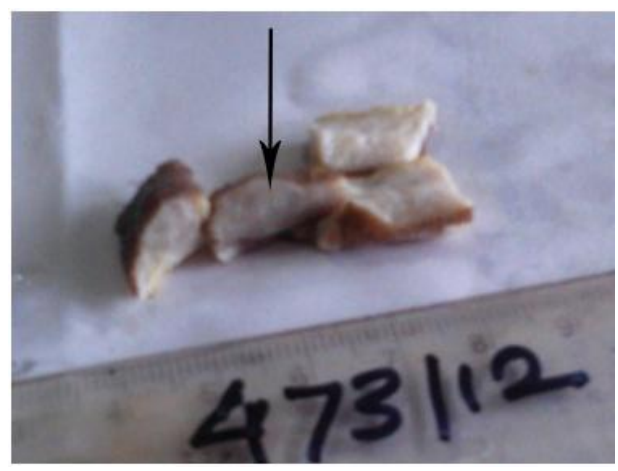

Fig. 1 cut section showing pear shaped or bulb like whitish gray dermal nodule (arrow)

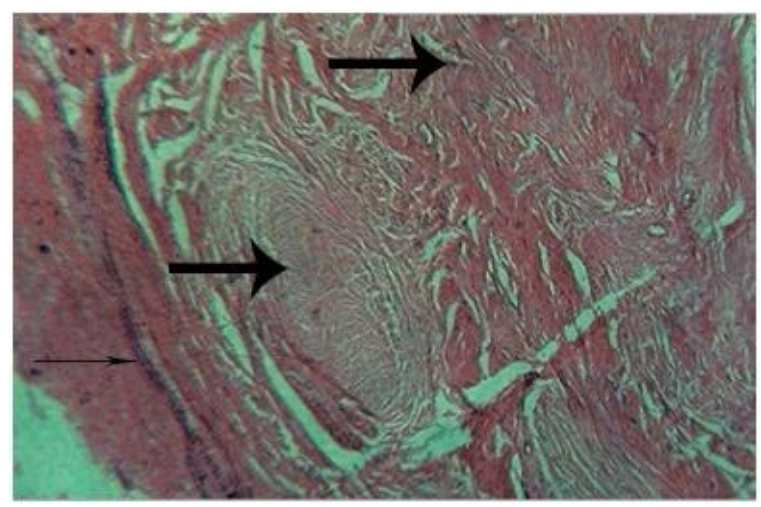

Fig 2: light microscopy of excised tumor showing nodules of nerve cells (thick arrow) with neurovascular bundle well circumscribed boundary (thin arrow) (HE stain, 10x) 


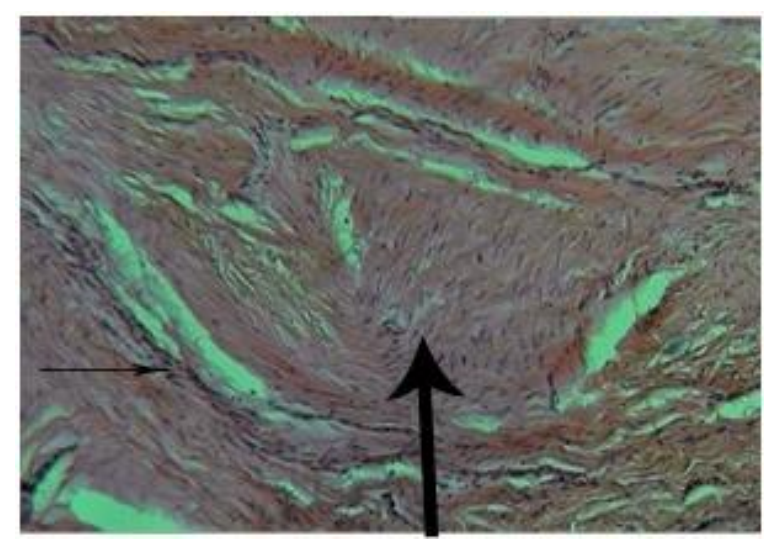

Fig. 3 neurovascular bundle (thin arrow) with fibro-collagenous nodularity (thick arrow)

\section{DISCUSSION}

Palisaded encapsulated neuroma (PEN), otherwise known as solitary circumscribed neuroma, was first described by Reed et al in $1972^{3,4}$. It is presented most commonly as a solitary lesion on the nose, cheek, forehead, eyelid, or lips. Clinically, lesion is firm nodule, papule, bulb like, pear shaped structure ${ }^{6}$ that simulates an intradermal nevus or basal cell carcinoma ${ }^{2}$. Palisaded encapsulated neuroma is a distinctive cutaneous nodular lesion often in the region of the central face. The lesions are benign and not associated with neurofibromatosis. Although they may be related to trauma, they differ from the classical traumatic neuroma ${ }^{1}$. No hairs are usually seen growing from their surface. Telangiectasia is usually minimal or absent and ulceration is only present after secondary trauma. The long duration of tumour, sparsity of telangiectasia, lack of ulceration, and circumscription may help to differentiate the PEN from a basal cell carcinoma. Intradermal naevi tend to be softer than these lesions and usually retain the overlying skin markings ${ }^{5}$. During biopsy, a lesion of PEN often is enucleated from its dermal bed and then submitted to the pathologist with little, if any, surrounding $\operatorname{skin}^{6}$.Macroscopically, the lesions are usually firm, well circumscribed whitish gray, intradermal, pear-shaped nodules. Histologically, the PEN is a well circumscribed, partially encapsulated spindle cell tumour. It consists of broad, interlacing, elongated fascicles of bland spindle cells. The fascicles appear distinct from one another and are often separated by artifactual clefts. The tumor cells are poorly delineated with eosinophilic cytoplasm, and pointed, wavy basophilic nuclei. No pleomorphism is seen and mitotic figures are rarely present. Occasional small blood vessels are seen in the stroma but haemorrhage and necrosis 
have

not

been

reported ${ }^{5}$. Immunohistochemically, the fascicles of tumor cells are positive for S-100 protein, vimentin and negative for $\alpha$-actin and Glial fibrillary acidic protein (GFAP) ${ }^{7}$. Silver stains (Bodian Silver Stain), immune reaction for neuron specific enolase and other neuronal proteins are suggested for axonal components.

There are several types of neuromas. Injury results into traumatic (amputation) neuroma. Irritation at fibro-osseous tissue is responsible for Morton's neuroma also called inter-metatarsal neuroma. Mucosal neuromas usually occur in multiple with genetic familial disorder MEN Ilb and III, which have autosomal dominant inheritance ${ }^{1}$.

Injury, irritation and genetic abnormality important role in genesis of certain neuronal hyperplasias and neuronal reactions like Morton's neuromas and familial disorder like MEN Ilb, mucosal neuromas syndrome (MNS) indicative of genetic aetiology ${ }^{2}$.

\section{CONCLUSION}

1) For this case, clinical and histopathological examination findings, peculiarly are in favor of Pallisaded encapsulated neuroma.

2) In our case there is a prominent fibroblastic component contributing to nodularity.

3) With regards to above clinical and histopathological peculiarities, both gross and microscopic, we considered a diagnosis of PEN.

4) PEN is a distinctive entity, often in face region and are benign.

5) Localised and circumscribed neuromas are considered as true neoplasm. 


\section{REFERENCES}

1. Stacey E. Mills, Darryl Carter, Joel K. Greenson, Victor E. Reuter, Mark H. Stoler: Sternberg's Diagnostic Surgical Pathology $5^{\text {th }}$ edition vol.1; Wolters Kluwer LWW 55, 73

2. Steven G. Silverberg, Ronald A. Delellis, William J. Frable :Principles and Practice of Surgical Pathology and Cytopathology, $3^{\text {rd }}$ edition vol. 3; Churchill Livingstone 453- 55, 2805-07

3. Juan Rosai, Rosai and Ackerman's Surgical Pathology $10^{\text {th }}$ edition vol.2;Elsevier-Mosby 2129-30

4. S.K. Repertinger, D.P. Sarma: Palisaded Encapsulated Neuroma (PEN). The Internet Journal of Dermatology. 2009 Volume 7 Number 2. DOI: 10.5580/1619 .

5. Sander $R$ Dubovy, Brian J Clark Palisaded encapsulated neuroma (solitary circumscribed neuroma of skin) of the eyelid Br J Ophthalmol 2001;85:949-51

6. Elder, David E.; Elenitsas, Rosalie; Johnson, Bernett L.; Murphy, George F. Lever's Histopathology of the Skin, $10^{\text {th }}$ Edition, Elsevier-Mosby ; 1134-38

7.Kayo Kuyama, Hirotaka Oomine, Yan Sun1, Masanobu Wakami, Hirotsugu Yamamoto. Open Journal of Stomatology, 2012, 2, 228-33doi:10.4236/ojst.2012.23040
Published Online September 2012

(http://www.SciRP.org/journal/ojst/)

8. Ivan Damjanov, James Linder, Anderson's Pathology $10^{\text {th }}$ edition, ElsevierMosby;2468-69 